\section{Recombination and directional selection}

FLEXON AND RODELL ${ }^{1}$ observed a correlated response for increased recombination in populations of Drosophila melanogaster selected for DDT resistance. Although they suggested that this correlated response is due to "hitchhiking', there are at least three possible explanations, one involving pleiotropy and two involving hitch-hiking. The initial conditions for all of them to occur are somewhat restrictive so that it is not possible to suggest a higher $a$ priori likelihood for any of them.

First, the alleles that confer resistance to DDT may have some pleiotropic effect that affects recombination. In other words, the mechanism of the resistance in this population may be such that it also influences the normal process of recombination.

Second, alleles increasing recombination may be carried along by (hitch-hike with) alleles that have resistance to DDT. In this case, the increase in recombination in itself does not affect fitness, that is, the level of recombination does not affect population fitness. Of course in another population or at another time, the alleles increasing resistance may be initially associated with alleles reducing recombination and a correlated response for reduced recombination would be observed. This hypothesis assumes that there is an initial positive association (gametic disequilibrium) between alleles increasing DDT resistance and alleles increasing recombination on both chromosomes II and III.

Third, the hypothesis advocated by Flexon and Rodell is that "recombinant genes generating genotypes favoured by selection can hitch-hike to increased allele frequencies". In this case, recombination results in the production of new gametes with an increased fitness that are associated with (in gametic disequilibrium with) an allele(s) for increased recombination. This last hypothesis is obtained from a theoretical model developed to show the potential evolutionary advantage of increased recombination. It assumes repulsion gametic disequilibrium among favourable alleles at fitness loci. Both hitch-hiking hypotheses assume tight linkage among the various genes involved.

From the data given, it appears that none of these hypotheses may be falsified and one cannot state that the results 'confirm' the last hypothesis but only that the data are consistent with all of these hypotheses.

This work was supported by NIH grant ROI HD 12731 to Glenys Thomson.

Note added in proof: It should be noted that the marker loci on chromosomes II and III, the chromosomes that showed increased recombination, span the centromeric heterochromatin and the markers on chromosome I do not. Knowledge of the distribution of crossovers, between- or intra-arm on chromosomes II and III might tell the significance of this difference.

\section{PHILIP W. HEDRICK}

\section{Department of Genetics, University of California, Berkeley, California 94720, USA}

1. Flexon, P. B. \& Rodell, C. F. Nature $298,672-674$ (1982)

RODELL REPLIES-Hedrick's expansion of our explanation for increased recombination frequency is both pertinent and welcomed. The possibility that high recombination rate alleles may be tightly linked to high DDT resistance alleles cannot be ruled out by our experiment. To make the distinction between coupling and repulsion gametic disequilibrium requires a system whereby both increased and decreased character expression can be selected. I have a selection experiment in progress involving sternopleural chaetae number in Drosophila melanogaster that will distinguish between these possibilities.

Hedrick's initial point, that high DDT resistance alleles may have a positive pleiotropic effect on recombination frequency, requires further comment. If the DDT resistance 'mechanism' is a cellular or organismal physiological phenomenon, it would seem that all chromosomes might be affected. We monitored chromosome regions encompassing 45.2, 88.0 and 16.8 map units for chromosomes I, II, and III, respectively. Because we observed significant recombination rate increases for chromosomes II and III but not for chromosome I, this explanation appears less likely than hitchhiking.

\section{CHARLES F. RODEll}

Department of Biology,

College of St Benedict,

St John's University,

Collegeville, Minnesota 56321, USA

\section{Leaching of nuclear waste forms}

BARKATT et al. ${ }^{1}$ have described the effects of radiolytic acidification of the aqueous medium on the leaching performances of various glass and ceramic waste forms, relative to their leaching performance in non-irradiated conditions in water of $p \mathrm{H} \sim 7$. They conclude that the leaching performance of the ceramic Synroc- $\mathrm{D}$ could deteriorate seriously in active conditions.
In response, I would first like to emphasize that the above experiments have no bearing on the performance of Synroc-C, the titanate ceramic designed to immobilize the high-level waste (HLW) arising from the reprocessing of spent fuel from civilian power reactors. Several independent laboratories have confirmed that Synroc-C is far more resistant to leaching than borosilicate glass over a wide range of temperatures and $p \mathrm{H}$ conditions.

Synroc-D is a specialized waste form with no application to the HLW which will be derived from reprocessing the inventories of spent fuel from commercial power reactors, which are widespread in Europe, the United States and Japan. Synroc-D is a specialized waste form designed solely to immobilize the wastes from the US Defense program that are held in tank storage at Savannah River and Hanford. Unlike commercial HLW, the defense wastes contain large quantities of processing contaminants, including iron, aluminium, sodium and silica. Thus, caesium is immobilized in the aluminosilicate phase nepheline, while the remaining radionuclides are incorporated in titanate phases (as in Synroc-C). Accordingly, the ability of Synroc-D to immobilize caesium is similar to borosilicate glass, whereas multivalent elements such as uranium and rare earths are about 1,000 times less easily leached from Synroc-D than from glass.

It is unfortunate that Barkatt et al. did not attempt to characterize their SynrocD sample, because some of this material now in circulation has not been fabricated according to my specifications. Thus, these samples contain in place of some or all of the nepheline, a low-silica, highalumina glass. Some strontium and calcium as well as caesium can be found in this glass. The fact that in acid conditions, leach rates increased for $\mathrm{Si}, \mathrm{Al}, \mathrm{Sr}$ and $\mathrm{Ca}$ as a group ${ }^{1}$, provides strong evidence for the presence of such a glass.

While Barkatt et al. have demonstrated that radiolysis can give rise to low $\mathrm{pH}$ conditions in the laboratory, it is important to realize that these $p \mathrm{H}$ levels are unlikely to prevail when a waste form is finally interred underground, because of buffering by surrounding repository rocks and canister overpacks. Aqueous solutions of $p \mathrm{H} \sim 6$ would be far more realistic.

\section{A. E. RINGWOOD}

Research School of Earth Sciences, Australian National University, PO Box 4, Canberra 2600, Australia

1. Barkatt, A., Barkatt, A. \& Sousanpour, W. Nature 300 , 339-341 (1982). 